\title{
Pressure is proinflammatory in lung venular capillaries
}

\author{
Wolfgang M. Kuebler, ${ }^{1}$ Xiaoyou Ying, ${ }^{1}$ Baljit Singh, ${ }^{1}$ Andrew C. Issekutz, ${ }^{2}$ \\ and Jahar Bhattacharya ${ }^{1}$
}

\begin{abstract}
${ }^{1}$ Department of Medicine and Department of Physiology and Cellular Biophysics, College of Physicians and Surgeons, Columbia University, St. Luke's-Roosevelt Hospital Center, New York, New York 10019, USA

${ }^{2}$ Department of Pediatrics, Microbiology-Immunology and Pathology, Dalhousie University, Halifax, Nova Scotia B3J 3G9, Canada

Address correspondence to: Jahar Bhattacharya, College of Physicians and Surgeons, Columbia University, St. Luke's-Roosevelt Hospital Center, 1000 10th Avenue, New York, New York 10019, USA. Phone: (212) 523-7310; Fax: (212) 523-8005; E-mail: jb39@columbia.edu.

Received for publication March 22, 1999, and accepted in revised form July 6, 1999.
\end{abstract}

Endothelial responses may contribute importantly to the pathology of high vascular pressure. In lung venular capillaries, we determined endothelial $\left[\mathrm{Ca}^{2+}\right]_{i}$ by the fura-2 ratioing method and fusion pore formation by quantifying the fluorescence of FM1-43. Pressure elevation increased endothelial $\left[\mathrm{Ca}^{2+}\right]_{i}$. Concomitantly evoked exocytotic events were evident in a novel spatial-temporal pattern of fusion pore formation. Fusion pores formed predominantly at vascular branch points and colocalized with the expression of P-selectin. Blockade of mechanogated $\mathrm{Ca}^{2+}$ channels inhibited these responses, identifying entry of external $\mathrm{Ca}^{2+}$ as the critical triggering mechanism. These endothelial responses point to a proinflammatory effect of high vascular pressure that may be relevant in the pathogenesis of pressure-induced lung disease.

J. Clin. Invest. 104:495-502 (1999).

\section{Introduction}

Although high microvascular pressure is well known to be pathogenic in major vascular beds such as lung and brain, cellular mechanisms that contribute to pressureinduced pathology in intact microvessels remain poorly understood. Of relevance are responses in endothelial cells that are subject not only to compressive effects of high vascular pressure, but also to possible stretchinduced effects occurring secondary to vascular distension. A large number of in vitro studies indicate that mechanically stretched endothelial cells evoke a variety of potentially proinflammatory responses, including cytokine secretion (1), superoxide production (2), secretion of monocyte chemotactic protein (3) and endothelin (4), increases of the cytosolic $\mathrm{Ca}^{2+}$ concentration $\left(\left[\mathrm{Ca}^{2+}\right]_{\mathrm{i}}\right)(5,6)$, and activation of tyrosine kinases $(7)$ and transcription factors (8). Such responses might underlie vascular pathology such as inflammation (9) or permeability increase (10) in pressure-induced lung disease.

A traditional difficulty in this understanding lies in the quantification of single-cell responses in situ. Recently, we addressed this issue through the application of fluorescence microscopy and digital imaging to venular capillaries of the isolated, blood-perfused rat lung. This approach, which enabled endothelial $\left[\mathrm{Ca}^{2+}\right]_{\mathrm{i}}$ quantification in the intact capillary (11), provided a means for testing endothelial responses to high capillary pressure. Specifically, we considered the possibility that stretchinduced effects of pressure may lead to $\mathrm{Ca}^{2+}$-dependent proinflammatory events such as the expression of the neutrophil-trafficking receptor P-selectin. Endothelial Weibel-Palade (WP) bodies store P-selectin (12) and undergo $\mathrm{Ca}^{2+}$-dependent exocytosis to express the receptor (13). Although P-selectin expression is almost unde- tectable in resting blood vessels $(14,15)$, the expression is enhanced by several injury stimuli $(12,16)$ and forms a hallmark of the early stage of inflammation (17).

A potential connection between high pressure and Pselectin exists in expression that cell mechanical factors play a role in exocytosis (18). Stretch-induced increases of endothelial $\left[\mathrm{Ca}^{2+}\right]_{\mathrm{i}}(5)$ may promote $\mathrm{Ca}^{2+}$-dependent, exocytotic vesicle-fusion events (19). This hypothesis is testable by the use of the styryl dye FM1-43, which is virtually nonfluorescent in aqueous media but fluoresces brightly upon binding cell membranes (20); it has been used extensively to detect exocytosis in neuronal (21-23) and non-neuronal $(24,25)$ cells. In FM1-43-treated cells, initiation of exocytosis increases fluorescence as the dye attaches to new membrane at the fusion pore (25). FM143 removal from the medium causes fluorescence decay as bound dye is lost from exocytotic vesicles (21-23). Based on these considerations, we determined FM1-43 fluorescence in conjunction with intravital quantifications of P-selectin expression and the endothelial $\left[\mathrm{Ca}^{2+}\right]_{\mathrm{i}}$ to obtain what we believe to be the first evidence for pressure-induced vascular exocytosis of P-selectin.

\section{Methods}

Fluorescent probes and drugs. Fura-2/AM and FM1-43 (both from Molecular Probes Inc., Eugene, Oregon, USA), trypan blue $(200 \mu \mathrm{M})$ and gadolinium chloride $\left(\mathrm{GdCl}_{3} ; 10 \mu \mathrm{M}\right)$ (both from Sigma Chemical Co., St. Louis, Missouri, USA), and mAb's were diluted in $2 \%$ dextran $(70 \mathrm{kDa}$; Pharmacia, Biotech Inc., Piscataway, New Jersey, USA), 1\% FBS (Gemini BioProducts, Calabasas, California, USA) Ringer's solution containing $144 \mathrm{mmol} / \mathrm{L} \mathrm{Na}^{+}, 4 \mathrm{mmol} / \mathrm{L} \mathrm{K}^{+}, 1.5 \mathrm{mmol} / \mathrm{L} \mathrm{Ca}^{2+}$, and $28 \mathrm{mmol} / \mathrm{L}$ lactate at $\mathrm{pH} 7.4$ and osmolarity of 300 
mOsm. We used the following mAb's: mouse anti-rat Pselectin mAb RMP-1 (35 $\mu \mathrm{g} / \mathrm{mL})(26)$, mouse anti-rat alveolar type I cell $\mathrm{mAb}(250 \mu \mathrm{g} / \mathrm{mL})(27)$, mouse antirat angiotensin-converting enzyme (ACE) mAb 4051 (50 $\mu \mathrm{g} / \mathrm{mL}$; Chemicon International, Temecula, California, USA) (28), goat anti-rat $\alpha \operatorname{IIb} \operatorname{IgG}(10 \mu \mathrm{g} / \mathrm{mL}$; Santa Cruz Biotechnology Inc., Santa Cruz, California, USA), FITCconjugated goat anti-mouse $\operatorname{IgG}\left(\mathrm{F}_{\mathrm{C}}\right.$-specific, 1:20; Sigma Chemical Co.), and FITC-conjugated donkey anti-goat IgG (1:20; ICN Biomedicals Inc., Costa Mesa, California, USA).

Fluorescence microscopy. Experimental procedures and setup have been described previously (11). In brief, lungs excised from anesthetized Sprague-Dawley rats were continuously pump-perfused with autologous rat blood $(14 \mathrm{~mL} / \mathrm{min})$ at $37^{\circ} \mathrm{C}$. Lungs were constantly inflated with positive airway pressure of $5 \mathrm{cmH}_{2} \mathrm{O}$. At baseline, pulmonary artery pressure $\left(\mathrm{P}_{\mathrm{PA}}\right)$ and left atrial pressure $\left(\mathrm{P}_{\mathrm{LA}}\right)$ were adjusted to 10 and $5 \mathrm{cmH}_{2} \mathrm{O}$, respectively. A microcatheter (PE-10; Baxter Diagnostics Inc., McGaw Park, Illinois, USA) was advanced through the left atrium and wedged in a pulmonary vein, allowing for local infusion of solutions (11). Lungs were positioned on a vibration-free air table. To prevent drying, the lung surface was superfused with normal saline at $37^{\circ} \mathrm{C}$.

Our methods for intravital fluorescence microscopy have been reported previously (11). Briefly, fluorophores were excited by mercury lamp illumination directed through appropriate filters. Fluorescence emission was collected through $\times 40$ objective lenses (for fura-2: Wplan FL 40× UV; for FITC and FM1-43: ULWD CDPlan 40PL; both from Olympus America Inc., Melville, New York, USA), dichroic and emission filters (for fura-2: 400DCLPO2 and 510WB40 [Omega Optical Inc., Brattleboro, Vermont, USA]; for FITC and FM1-43: BP490 [Olympus America Inc.]), image-intensifier (KS1381; Video Scope International, Sterling, Virginia, USA), and video camera (CCD-72; Dage-MTI Inc., Michigan City, Indiana, USA), and was then subjected to digital image analysis (MCID-M4; Imaging Research Inc., St. Catharine's, Ontario, Canada). Single venular capillaries were viewed at a focal plane corresponding to maximum diameter $(12-20 \mu \mathrm{m})$.

$\left[\mathrm{Ca}^{2+}\right]_{i}$ imaging. Lung endothelial $\left[\mathrm{Ca}^{2+}\right]_{\mathrm{i}}$ was quantified using our fura-2 ratiometric imaging technique, described previously (11). Membrane-permeant fura2/AM $(5 \mu \mathrm{M})$, which de-esterifies intracellularly to impermeant fura-2, was infused for 20 minutes into pulmonary venular capillaries using the venous microcatheter. Fluorescence images were obtained at 10 -second intervals. For each image, 4 frame-averaged sets of exposures were obtained that alternated every 33 milliseconds between excitations of 340 and $380 \mathrm{~nm}$. Endothelial $\left[\mathrm{Ca}^{2+}\right]_{\mathrm{i}}$ was determined from the computergenerated 340:380 ratio based on a $\mathrm{K}_{\mathrm{d}}$ of $224 \mathrm{nmol} / \mathrm{L}$ and appropriate calibration parameters $(11,29)$.

Fusion pore imaging. For quantification of fusion pore formation in lung microvessels, lung perfusion was stopped, and the styryl dye FM1-43 (4 $\mu \mathrm{M}$ in dextran Ringer's solution) was infused for 5 minutes into pulmonary venular capillaries using the venous microcatheter. Then, intravascular FM1-43 was washed out by reinstatement of blood flow. Fluorescence images were obtained continuously at 5-second intervals. Capillary fluorescence indicative of fusion pore formation was quantified during 5 minutes of FM1-43 infusion.

P-selectin imaging. Endothelial P-selectin expression in intact lung microvessels was determined using immunofluorescence methods. During a brief stop of pulmonary perfusion, primary antibody (anti-Pselectin RMP-1 or control antibodies such as anti-alveolar type I cell $\mathrm{mAb}$, anti-ACE mAb, or anti- $\alpha$ IIb antibody) was infused into a single subpleural venular capillary by micropuncture and incubated for $10 \mathrm{~min}$ utes. Then, the identical vessel was remicropunctured, and the secondary FITC-conjugated mAb was infused. After a 1-minute incubation, unbound FITC fluorescence was removed by reinstatement of blood flow. Residual FITC fluorescence indicative of vascular antigen expression was monitored in 5-second intervals from 60 seconds after restart of perfusion until complete absence of fluorescence signal.

Experimental groups. (a) Pressure elevation: Baseline recordings were obtained at $\mathrm{P}_{\mathrm{LA}}$ of $5 \mathrm{cmH}_{2} \mathrm{O}$. $\mathrm{P}_{\mathrm{LA}}$ was raised to $20 \mathrm{cmH}_{2} \mathrm{O}$ for 30 minutes by adjusting the height of the venous outflow. (b) Inhibition of stretchactivated cation channels: The trivalent lanthanide gadolinium $(10 \mu \mathrm{M})$, which effectively blocks stretchactivated cation channels (30), was added to the perfusing blood 10 minutes before $\mathrm{P}_{\mathrm{LA}}$ elevation. (c) $\mathrm{Ca}^{2+}$-free conditions: $\mathrm{Ca}^{2+}$-free Ringer's solution containing $2 \%$ dextran and EGTA $(0.5 \mathrm{mmol} / \mathrm{L})$ was infused through the venous microcatheter 10 minutes before $P_{L A}$ elevation. (d) Platelet-poor perfusion: Fresh blood of known hematocrit was centrifuged, and the supernatant above the buffy coat was discarded. Red blood cells and buffy coat were then resuspended in a volume of $2 \%$ dextran Ringer's solution to reestablish baseline hematocrit. Platelet counts in platelet-poor perfusate were $20 \%$ of those in fresh blood (31). (e) Lung cooling: Before measurements were taken, lungs were cooled to $4^{\circ} \mathrm{C}$ for 30 minutes by running the perfusate through an ice bath.

Statistics. All data are mean \pm SEM. Values of several groups were compared by Wilcoxon and Friedman test for dependent groups and by Kruskal-Wallis and MannWhitney $U$ test for independent groups. Spearman's coefficient of correlation $\left(r_{\mathrm{s}}\right)$ was calculated to test correlation between parameters, and linear regression analysis was performed (SigmaPlot; Jandel Scientific, San Rafael, California, USA). Statistical significance was assumed at $P<0.05$.

\section{Results}

Pressure-induced increase of endothelial $\left[\mathrm{Ca}^{2+}\right]_{i}$. To determine the effects of increasing $\mathrm{P}_{\mathrm{LA}}$, we quantified endothelial $\left[\mathrm{Ca}^{2+}\right]_{i}$ in digitally imaged, single venular capillaries of the isolated, blood-perfused rat lung (11). Determinations were obtained at $\mathrm{P}_{\mathrm{LA}}$ of $5 \mathrm{cmH}_{2} \mathrm{O}$, at which capillary pressure is at physiological levels (32), and after 30 minutes at $\mathrm{P}_{\mathrm{LA}}$ of $20 \mathrm{cmH}_{2} \mathrm{O}$. Corresponding $\mathrm{P}_{\mathrm{PA}}$ were 10 and $24 \mathrm{cmH}_{2} \mathrm{O}$, respectively. As shown in Figure 1, increase of $\mathrm{P}_{\mathrm{LA}}$ increased mean $\left[\mathrm{Ca}^{2+}\right]_{\mathrm{i}}$ by $60 \%$. Return to baseline pressures reestablished baseline $\left[\mathrm{Ca}^{2+}\right]_{\mathrm{i}}$ levels within 5 minutes (not shown). Gadolinium-inhibitable 
channels are identified as a primary mechanism for $\mathrm{Ca}^{2+}$ mobilization in stretched cells (5). Consistent with this notion, gadolinium infusion in these capillaries before pressure challenge abolished the endothelial $\left[\mathrm{Ca}^{2+}\right]_{\mathrm{i}}$ increase (Figure 1b). Similar inhibition was obtained in the presence of capillary infusions of $\mathrm{Ca}^{2+}$-free dextran. These findings are consistent with the interpretation that entry of external $\mathrm{Ca}^{2+}$ through stretch-activated channels caused the pressure-induced $\left[\mathrm{Ca}^{2+}\right]_{\mathrm{i}}$ increases.

Fusion pores. Microinfusions of FM1-43, given for 5 minutes under baseline conditions, resulted in spotty but sparse fluorescence localized mainly at vessel branch points. The number of fluorescent spots, which were $1-4 \mu \mathrm{m}$ in diameter, increased markedly when a similar infusion was given after increasing $\mathrm{P}_{\mathrm{LA}}$ to 20 $\mathrm{cmH}_{2} \mathrm{O}$ for 30 minutes (Figure 2a). The fluorescence increased in a time-dependent manner during FM1-43 infusion, but was lost in $53 \pm 4$ seconds after stopping the infusion and reinstating blood flow to wash out FM1-43 from the capillary lumen (Figure 2b). No residual fluorescence was detectable.

These fluorescence responses are essentially similar to FM1-43-loaded cultured cells undergoing exocytosis $(21,22,25)$, and signify the presence of pressureinduced exocytotic fusion pore formation in these capillaries. To rule out nonspecific mechanisms for the fluorescence decay, we tested the effects of prolonged dye infusion under baseline pressure conditions. FM143 infusion for 30 minutes resulted in more extensive fluorescence staining of the endothelial surface (data not shown). However, after FM1-43 washout, fluorescence decay occurred in $14 \pm 3$ seconds, which was faster than for the pressure-elevated condition $(n=4$; $P<0.05)$. This faster fluorescence decay reflects the time taken for membrane destaining by nonspecific mechanisms. Hence, as we discuss later, the more prolonged fluorescence decay under pressure-stressed conditions reflected ongoing exocytosis of recycling vesicles that had been labeled and internalized during the FM1-43 infusion.

Under pressure-stressed conditions, a characteristic feature was that fluorescence of FM1-43 appeared at different times in different regions within the same imaged field, as exemplified by the images in Figure 2a. The predominant sites of expression were the vessel branch points $(P<0.05)$. After pressure elevation, fluorescence increase at branch points was at least 2 -fold greater than at interbranch capillary midsegments (Figure 2c). The pressure-augmented exocytosis was rapidly reversible, because FM1-43 fluorescence returned to baseline values concomitantly with return of $\mathrm{P}_{\mathrm{LA}}$ to baseline (not shown). Similar to the $\left[\mathrm{Ca}^{2+}\right]_{i}$ responses, the pressure-induced increase of FM1-43 fluorescence was blocked by gadolinium (Figure $2 c ; P<0.05$ ). This result rules out nonspecific causes for the fluorescence increase and indicates that the enhanced fusion pore formation resulted from mechanisms involving stretch-activated channels.

P-selectin. WP bodies containing P-selectin are likely candidates for endothelial exocytosis. To detect Pselectin expression, we microinfused venular capillaries with anti-P-selectin $\mathrm{mAb}$ and then with FITC-conjugated secondary IgG. In capillaries imaged after wash-

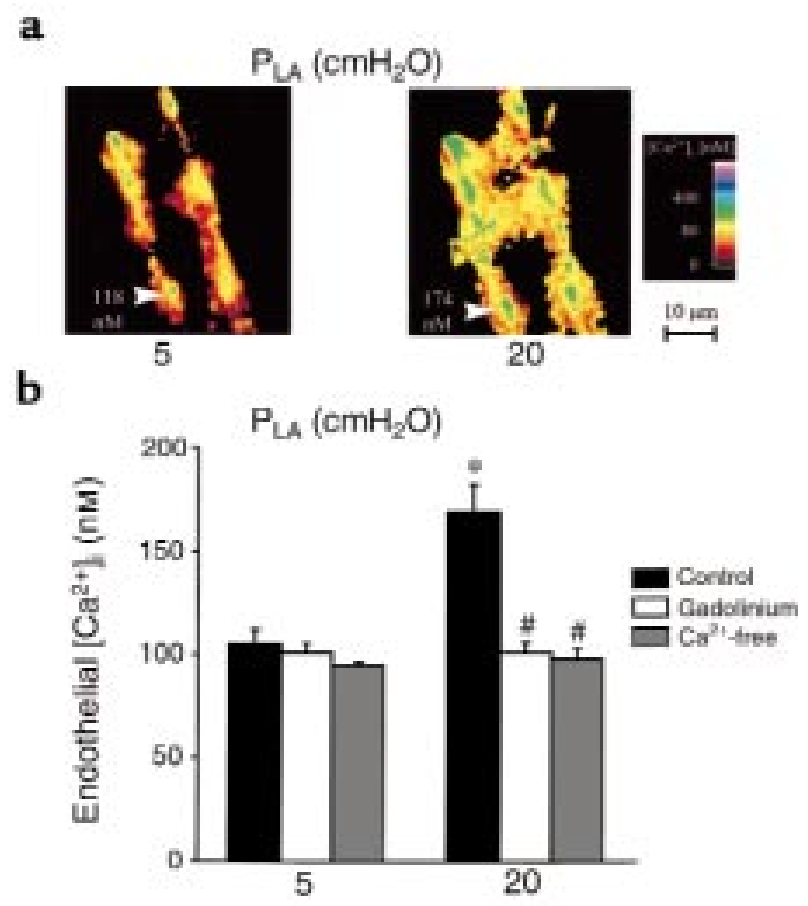

Figure 1

Endothelial $\left[\mathrm{Ca}^{2+}\right]_{\mathrm{i}}$ in lung venular capillaries. (a) Images are of the 340:380

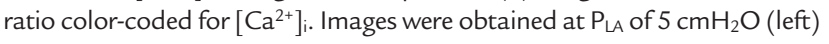
and after 30 minutes of $P_{L A}$ increase to $20 \mathrm{cmH}_{2} \mathrm{O}$ (right). Endothelial $\left[\mathrm{Ca}^{2+}\right]_{\mathrm{i}}$ is given for a single cell (arrowheads). Replicated in 9 capillaries. (b) Group data are shown as 5-minute averages at $\mathrm{P}_{\mathrm{LA}}$ of $5 \mathrm{cmH}_{2} \mathrm{O}$ and after 30 minutes of $\mathrm{P}_{\mathrm{LA}}$ increase to $20 \mathrm{cmH}_{2} \mathrm{O}$. Infusions of gadolinium $(n=4)$ or $\mathrm{Ca}^{2+}$-free dextran $(n=4)$ were started 10 minutes before pressure elevation. ${ }^{*} P<0.05$ vs. P $\mathrm{LA}$ of $5 \mathrm{cmH}_{2} \mathrm{O} ;{ }^{\#} P<0.05$ vs. control $(n=9)$.

ing out unbound fluorescence from the vessel lumen by reinstatement of blood flow, fluorescence was weak at baseline but increased 12-fold after $\mathrm{P}_{\mathrm{LA}}$ elevation (Figure 3 , a and $b ; P<0.05)$. As exemplified by the experiment in Figure 3a (right), the increased P-selectin expression occurred throughout the vessel length, both at the midsegmental region (arrow) and at the branch point (arrowhead). However, the expression was greater at branch points, as indicated by the green pseudocolor. Hence, pressure-stress increased P-selectin expression. Although gadolinium given under baseline conditions had no effect on P-selectin expression (not shown), the blocker abolished the enhanced P-selectin expression (Figure 3b; $P<0.05$ ), indicating involvement of mechanogated cation channels in the P-selectin response to pressure stress.

Complete removal of fluorescence by infusion of the extracellular fluorescence quencher trypan blue (not shown) confirmed that the pressure-induced fluorescence enhancement occurred on the luminal surface of the capillary. To rule out nonspecific mechanisms that may have contributed to the fluorescence, we infused FITC-IgG either alone or after infusing an isotypematched $\mathrm{mAb}$ that recognizes rat tissue but not endothelium (27). In either case, the fluorescence was completely removed by blood flow in $20 \pm 1$ seconds $(n=6)$, whereas our data were obtained after 60 seconds of washout. 
a

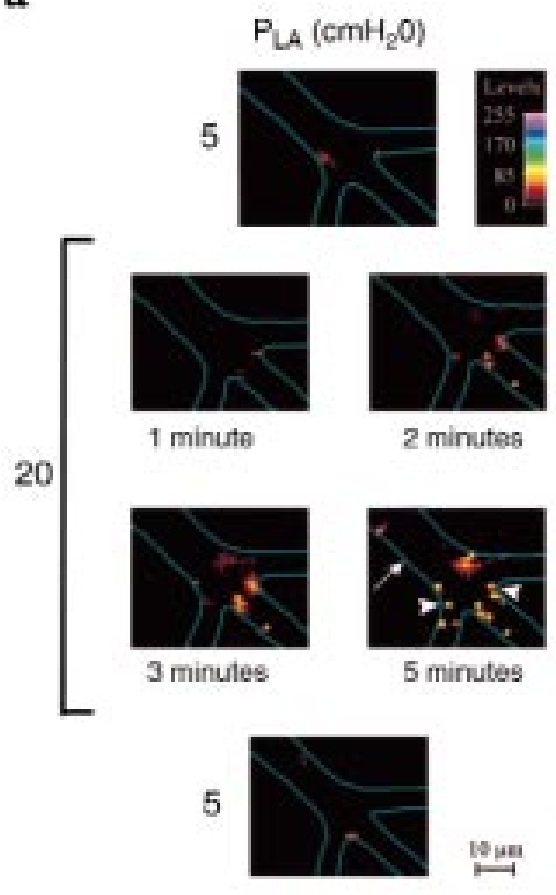

b
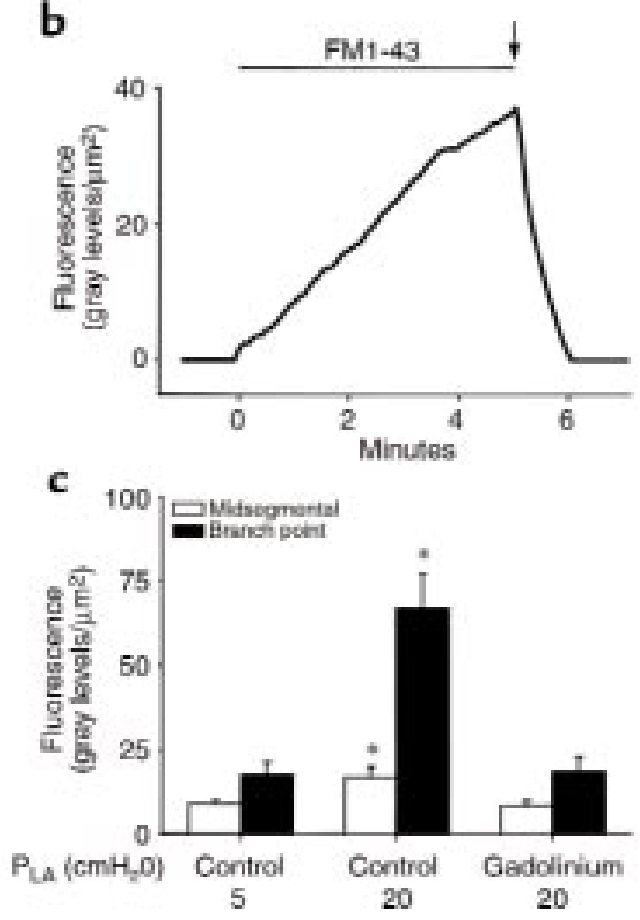

Figure 2

Fusion pore formation in lung venular capillaries. (a) Images of a single capillary taken at different $\mathrm{P}_{\mathrm{LA}}$. $\mathrm{P}_{\mathrm{LA}}$ of $5 \mathrm{~cm} \mathrm{H}_{2} \mathrm{O}$. Images are before (top) and after (bottom) pressure elevation was obtained after 5 minutes of FM1-43 infusion. $\mathrm{P}_{\mathrm{LA}}$ of $20 \mathrm{~cm} \mathrm{H}_{2} \mathrm{O}$. Images were obtained at different time points after start of dye infusion. Color code shows fluorescence intensities. Capillary branch point (arrowheads) and midsegmental (arrow) locations are marked. Vessel margins are depicted by line sketches. Replicated in 8 capillaries. (b) After 30 minutes at $\mathrm{P}_{\mathrm{LA}}$ of $20 \mathrm{~cm} \mathrm{H}_{2} \mathrm{O}$, FM1-43 was infused into a lung venular capillary (horizontal bar) and then washed out by the blood flow (arrow). Shown is capillary fluorescence per unit surface area. Replicated in 8 capillaries. (c) Capillary fluorescence was quantified in pixels $5 \times 5 \mu \mathrm{m}^{2}$, at midsegmental and branch point locations after 5 minutes of FM1-43 infusion. Data were obtained at $\mathrm{P}_{\mathrm{LA}}$ of $5 \mathrm{~cm} \mathrm{H}_{2} \mathrm{O}$ and after 30 minutes of $\mathrm{P}_{\mathrm{LA}}$ increase to $20 \mathrm{~cm} \mathrm{H}_{2} \mathrm{O}$ in control $(n=8)$ and gadolinium-treated $(n=4)$ lungs. Gadolinium did not increase fluorescence above control at $\mathrm{P}_{\mathrm{LA}}$ of $5 \mathrm{~cm} \mathrm{H}_{2} \mathrm{O}$ (not shown). ${ }^{*} P<0.05$ vs. $\mathrm{P}_{\mathrm{LA}}$ of $5 \mathrm{~cm} \mathrm{H}_{2} \mathrm{O}$.

Hence, the fluorescence enhancement was not attributable to trapped FITC-IgG in the infused capillary.

Because platelets also express P-selectin (33), we conducted several experiments to rule out the possibility that platelet deposition causes the P-selectin immunofluorescence. These experiments (data not shown) indicated that in capillaries held either at baseline or at high pressure, immunofluorescence attributable to a platelet-specific antigen, $\alpha \mathrm{IIb}$ (CD41, GPIIb), was completely absent $(n=3)$. However, as expected, the anti- $\alpha I I b$ antibody strongly stained platelets in whole blood. Moreover, in 4 experiments, we reconfirmed our previous finding that platelet-endothelial adhesion is not histologically evident in these isolated lungs (34). Therefore, platelets were not deposited in these capillaries. In other experiments, we continuously infused dextran Ringer's solution into venular capillaries for 5 minutes by venous microcatheter to remove blood from experimental microvessels. The pressure-induced P-selectin immunofluorescence in these capillaries was identical to that of blood-perfused capillaries $(n=3)$. Moreover, similar responses were obtained in lungs perfused with platelet-poor blood $(n=$ 3 ). Based on these findings, we conclude that the present P-selectin immunofluorescence was attributable to endothelial, not platelet-derived, antigens.

Previously, we determined that the endothelial fluorescence of the luminal $\alpha_{v} \beta_{3}$ integrin of lung capillaries remains stable with time (34). Similarly, the immunofluorescence of another stable endothelial antigen, ACE, remained unchanged for more than 10 minutes (not shown). By contrast, at $\mathrm{P}_{\mathrm{LA}}$ of $5 \mathrm{cmH}_{2} \mathrm{O}$, P-selectin fluorescence decayed to $25 \%$ of initial levels within 2 minutes (Figure 3b). By linear regression analyses of the fluorescence data, we established that pressure elevation doubled the rate of fluorescence decay $(P<0.05)$, indicating that pressure stress enhanced both expression and removal of P-selectin.

Cooling the lung to $4^{\circ} \mathrm{C}$ stabilized P-selectin fluorescence (Figure $3 \mathrm{~b}$ ). We interpret from this result, first, that the P-selectin removal from the endothelial surface was not attributable to washout by the blood flow, and second, that the removal was by active cellular mechanisms, involving possible cellular reinternalization of Pselectin $(35,36)$ or shedding of its ectodomain (37). These findings indicate that pressure-induced increases of exocytosis and removal of P-selectin combined to enhance endothelial P-selectin turnover.

Spatial correlations. As shown in the images in Figure 3a, P-selectin expression was higher at branch points than at midsegments. The similarity to the fusion pore distribution was confirmed in a pixel-by-pixel correlation analysis of the fluorescence attributable to FM1-43 and P-selectin (Figure 4, a and b). Cell-by-cell analyses inclusive of baseline and pressure-elevation data gave linear 
correlations of endothelial $\left[\mathrm{Ca}^{2+}\right]_{\mathrm{i}}$ with fluorescences of FM1-43 and P-selectin (Figure 4c). These considerations indicate that P-selectin expression colocalized with fusion pore formation and that cells with higher $\left[\mathrm{Ca}^{2+}\right]_{i}$ supported higher levels of P-selectin exocytosis.

\section{Discussion}

Pressure elevation in the lung venular capillary increased endothelial $\left[\mathrm{Ca}^{2+}\right]_{\mathrm{i}}$, augmented endothelial exocytosis, and enhanced luminal expression of P-selectin. All 3 increases were inhibited by gadolinium, the blocker of mechanogated cation channels. These findings are novel evidence that high vascular pressure evokes exocytotic events in capillary endothelium and that underlying mechanisms involve $\mathrm{Ca}^{2+}$ entry through mechanogated channels. Because P-selectin mediates neutrophil rolling as part of the early inflammatory response $(17,38)$, its enhanced expression here reflects a purely pressure-induced mechanism for the initiation of vascular inflammation.

Exocytosis. A novel feature of these pressure-induced responses was the formation of fusion pores, as indicated in the fluorescence of FM1-43. Tracing fusion pore locations allowed an understanding of the patterns of Pselectin expression. Previous reports indicate that FM143 fluorescence is punctate (24) and may be localized to specific exocytotic sites (25). Here, the fluorescence appeared as single spots of up to $4 \mu \mathrm{m}$ in diameter that probably resulted from formation of fusion pore clusters or exocytosis of large vesicles such as WP bodies (39). The inhibitory effects of gadolinium indicate that $\left[\mathrm{Ca}^{2+}\right]_{\mathrm{i}}$ increase attributable to entry of external $\mathrm{Ca}^{2+}$ triggered these exocytotic events.

Consistent with the notion that P-selectin is exocytosed (16), sites of P-selectin expression colocalized with these fluorescence clusters. A novel feature was that the enhanced fusion pore formation at high pressure appeared in a random spatial pattern. Because the evoked fluorescent spots appeared within as little as 3 $\mu \mathrm{m}$ of one another, an endothelial cell evidently supported exocytosis at several locations on its luminal plasma membrane. The basis for this spatially random expression pattern remains unclear, although dispersal of fusion pore formation on the cell surface may effect a spatial integration that best ensures availability and continuity of new receptor expression.

When secretory vesicles are recycled, as in synapses (21), FM1-43 is incorporated into internalized vesicles. Subsequent loss of fluorescence during stimulation of dye-loaded cells under external FM1-43-free conditions signifies exocytosis of recycled vesicles (21-23). At high pressure, FM1-43 infusions caused progressive increase of fluorescence that is possibly attributable to membrane binding and internalization of the dye at sites of fusion pore formation. Removal of FM1-43 by reinstating blood flow resulted in fluorescence loss in about 50 seconds, which was considerably longer than nonspecific removal of the dye and, therefore, reflects fluorescence release from newly fusing vesicles. The fluorescence loss was unlikely to be due to transcytotic processes that are much slower and occur over several minutes $(40,41)$ or to endocytosis and cellular retention of FM1-43 that would sustain cellular fluorescence $(24,25)$. Hence, the fluorescence loss reflects progressive exocytosis of recycled vesicles. Because FM1-43 was infused for 5 minutes and fluorescence loss occurred in less than 1 minute, we estimate vesicle recycling time to be 1-6 minutes, which is in the range of recycling times reported in neuronal cells (21). These considerations lead to the novel understanding that high pressure is a secretory stimulus in blood vessels and induces exocytotic fusion pore formation.

P-selectin expression. To our knowledge, we provide the first direct evidence that high pressure induces P-selectin expression in lung microvessels, a finding that is relevant to mechanisms of lung injury. P-selectin is implicated in such mechanisms, because lung injury after complement activation or ischemia-reperfusion is attenuated by anti-P-selectin antibody $(42,43)$. In stimulated endothe-

a

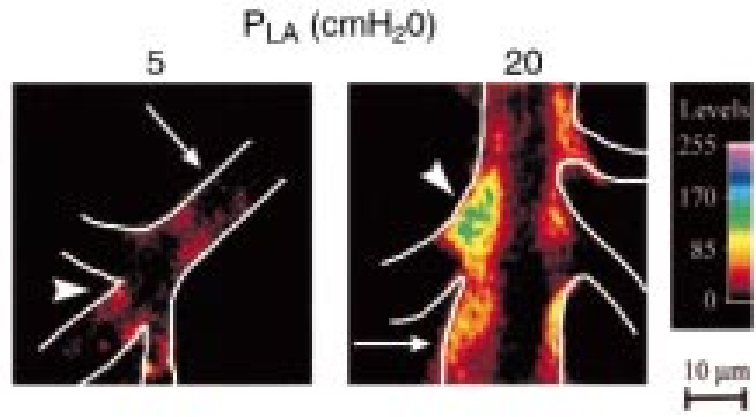

b

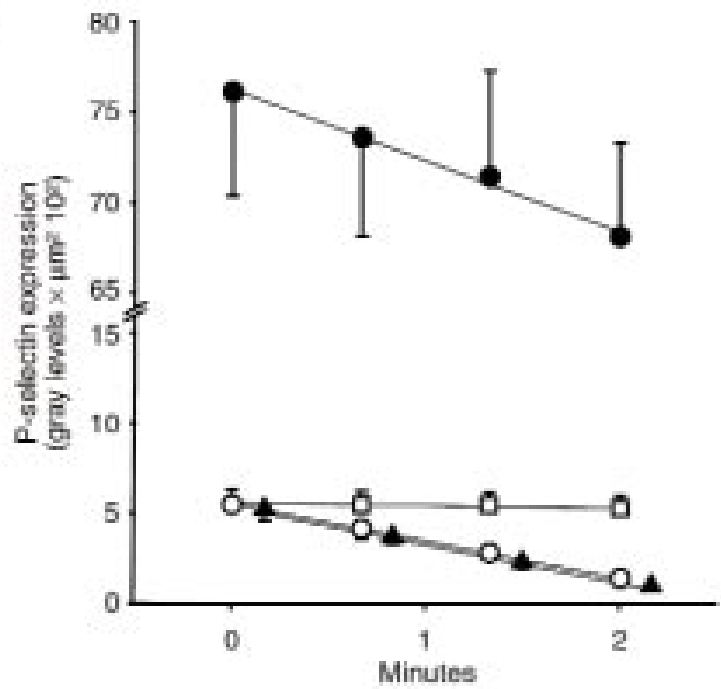

Figure 3

P-selectin expression in lung venular capillaries. (a) Images show indirect immunofluorescence of P-selectin at $\mathrm{P}_{\mathrm{LA}}$ of $5 \mathrm{~cm} \mathrm{H}_{2} \mathrm{O}$ (left) and after 30 minutes of $P_{L A}$ increase to $20 \mathrm{~cm} \mathrm{H}_{2} \mathrm{O}$ (right). Vessel margins are depicted by line sketch. Color code shows fluorescence intensities at branch point (arrowheads) and midsegmental (arrows) locations. Replicated in 8 capillaries. (b) P-selectin expression was quantified as the product of the mean fluorescence intensity and fluorescent area. The $x$-axis indicates period elapsed after a 1-minute washout of unbound FITC-IgG with blood flow. Data were obtained at $\mathrm{P}_{\mathrm{LA}}$ of $5 \mathrm{~cm} \mathrm{H}_{2} \mathrm{O}$ (open symbols) and after 30 minutes of $P_{L A}$ increase to $20 \mathrm{cmH}_{2} \mathrm{O}$ (filled symbols). Plots are control (circles; $n=8$ ), $4^{\circ} \mathrm{C}$ (squares; $n=3$ ), and gadolinium treatment (triangles; $n=4)$. Decay of P-selectin fluorescence was determined from the linear regression slope $(P<0.01$ for all regressions). 
a

FM1-43
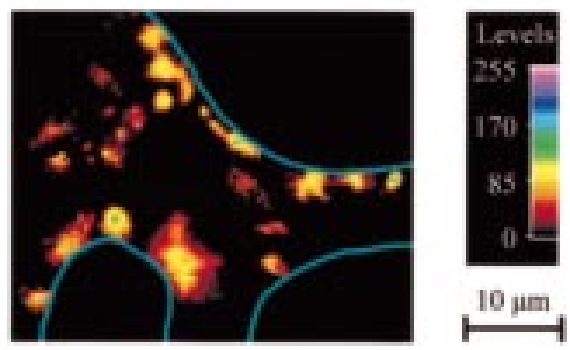

P-selectin

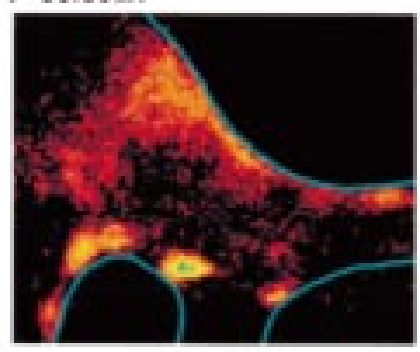

b

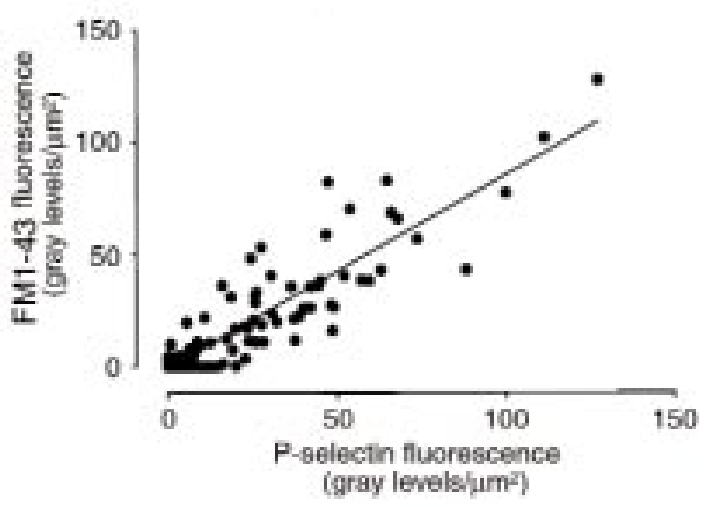

c

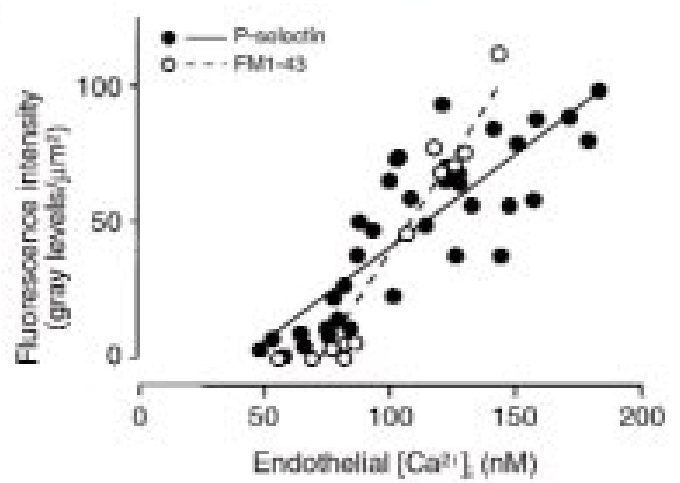

Figure 4

$\left[\mathrm{Ca}^{2+}\right]_{i}$ dependence of fusion pore formation and P-selectin expression in lung venular capillaries. (a) Images of a pressure-stressed lung capillary at a branch point. After 30 minutes at $P_{L A}$ of $20 \mathrm{~cm} \mathrm{H}_{2} \mathrm{O}$, FM1-43 was infused for 5 minutes, and the capillary was imaged at a specific, landmarked location (top). Subsequently, FM1-43 fluorescence was photobleached by exposure to unfiltered mercury lamp illumination, and the capillary was stained for P-selectin expression and then reimaged at the identical location (bottom). Line sketches depict vessel margins. Replicated in 6 capillaries. (b) Single vessels were consecutively stained with FM1-43 for fusion pore detection and for indirect immunofluorescence of P-selectin at $P_{L A}$ of 5 and 20 $\mathrm{cmH}_{2} \mathrm{O}$. Graph shows data from pixel-by-pixel analyses (pixel size: $\left.5 \times 5 \mu \mathrm{m}^{2}\right)$. Line was drawn by linear regression $\left(r_{\mathrm{s}}=0.781 ; P<0.001 ; n=11\right)$. (c) Endothelial $\left[\mathrm{Ca}^{2+}\right]_{i}$ was correlated with expressions of fusion pores and P-selectin. Data were obtained at $\mathrm{P}_{\mathrm{LA}}$ of 5 and $20 \mathrm{cmH} \mathrm{H}_{2} \mathrm{O}$. After determination of endothelial $\left[\mathrm{Ca}^{2+}\right]_{\text {, fura-2 }}$ fluorescence was photobleached, and vessels were stained with FM1-43 for fusion pore fluorescence $($ open circles; $n=4$ ) or for immunofluorescence of P-selectin (filled circles; $n=6$ ). FM1-43 and P-selectin fluorescences were quantified in $5 \times 5 \mu \mathrm{m}^{2}$ pixels at sites of [Ca $\left.{ }^{2+}\right]_{\mathrm{i}}$ determination. Lines were drawn by linear regressions for FM1-43 $\left(r_{\mathrm{s}}=0.949 ; P<0.001\right)$ and P-selectin $\left(r_{\mathrm{s}}=0.826 ; P<0.001\right)$ against $\left[\mathrm{Ca}^{2+}\right]_{\text {. }}$.

lial cells, P-selectin is rapidly internalized (16) and either sorted to the Golgi (35) and WP bodies for receptor reexpression (44) or targeted to lysosomes in order to prevent recycling (36). The presence of soluble P-selectin in plasma $(45,46)$ suggests that its ectodomain may be shed from endothelial cells (37). Consistent with previous reports, $\mathrm{P}$-selectin expression in lung microvessels was barely detectable at baseline $(14,15)$. In contrast, high pressure not only increased P-selectin expression, but also increased the rate of P-selectin removal from the capillary surface. The increase of expression was considerably greater than the increase of the removal rate, suggesting that removal mechanisms may follow saturation kinetics. Under pressure stress, mechanisms of rapid vesicle recycling and receptor shedding may act together to maintain optimal P-selectin expression.

Spatial distribution. Expression of P-selectin and exocytotic fusion pores occurred both at branch points and midsegmental locations of the lung venular capillary. This spatial continuity of endothelial receptor expression allows leukocytes to roll along the length of the microvessel $(47,48)$, and probably results from the spatial and temporal dispersal of vesicle exocytosis. However, pressure-enhanced exocytosis occurred primarily at capillary branch points. A rheological explanation for this site dominance may be considered, because in large vessels, branch points are associated with increased turbulence and changing gradients of shear rate (49). However, the low Reynolds number flow in lung capillaries prevents turbulence and maintains relatively low shear rates (48). Hence, exocytosis dominance at branch points was unlikely to be due to rheological factors. An explanation for the site dominance may lie in the distribution of endothelial $\left[\mathrm{Ca}^{2+}\right]_{\mathrm{i}}$ in lung capillaries. Previously, we reported that $\left[\mathrm{Ca}^{2+}\right]_{\mathrm{i}}$ is highest at branch point endothelial cells of lung venular capillaries (11). Here we show that the extent of exocytosis correlates with endothelial $\left[\mathrm{Ca}^{2+}\right]_{i}$. Therefore, we interpret that the higher endothelial $\left[\mathrm{Ca}^{2+}\right]_{\mathrm{i}}$ at branch points orders the increased exocytosis. Increased P-selectin exocytosis at microvascular branch points may facilitate tethering and initiate rolling of neutrophils emerging out of the alveolar capillary bed.

These findings underscore the pathophysiological significance of the post-alveolar venular capillary. Although 
larger numbers of leukocytes accumulate in alveolar capillaries $(47,50)$, a significant amount of neutrophil adhesion occurs in post-alveolar venular capillaries $(47,48)$. In some forms of injury, such as trauma, P-selectin expression is almost exclusively restricted to venular capillaries (51). Because venular capillaries are the most permeable vessels of the lung microvascular bed (52) and are capable, through specific venoconstriction, of increasing lung capillary pressures (53), mechanisms of neutrophil adhesion in the lung venular capillary may contribute importantly to the development of lung injury.

Clinical significance. Finally, the clinical relevance of our findings relates to the controversial question of whether an increase of pressure results in deleterious lung vascular effects. Traditionally, increase of vascular pressure is thought to passively increase fluid filtration by causing an imbalance of Starling forces (54). However, recent reports indicate that the lung vascular response to high pressure may be more complex. Increase of $\mathrm{P}_{\mathrm{LA}}$ to 20-50 $\mathrm{cmH}_{2} \mathrm{O}$ increases the lung capillary filtration coefficient $(10,55)$ and enhances transvascular protein flow $(56)$. Higher increases of the pressure $\left(>50 \mathrm{cmH}_{2} \mathrm{O}\right)$ cause capillary breaks $(57,58)$ and more intense permeability increases (59). Clinically, lungs subjected to high-pressure insult, as in hydrostatic edema or high-altitude pulmonary edema, show evidence of inflammation, because the bronchoalveolar lavage fluid has increased white cells and elevated levels of inflammatory cytokines ( 9 , 60-62). Our findings are consistent with these reports. The endothelial $\left[\mathrm{Ca}^{2+}\right]_{i}$ increase, a potential cause for endothelial retraction (63), and the enhanced P-selectin expression, a potential white cell adhesion mechanism $(17,38)$, may underlie the permeability and inflammatory effects of high pressure. Importantly, we show that lung endothelial cells respond actively and rapidly to the challenge of high pressure.

\section{Acknowledgments}

Anti-alveolar type I cell mAb was kindly provided by L. Dobbs (Cardiovascular research Institute, University of California-San Francisco, San Francisco, California, USA). This study was supported by National Institutes of Health grants HL-57556, HL-36024, and HL-53625. W.M. Kuebler is a Research Fellow of the Deutsche Forschungsgemeinschaft (1997-1999).

1. Okada, M., et al. 1998. Cyclic stretch upregulates production of interleukin- 8 and monocyte chemotactic and activating factor/monocyte chemoattractant protein-1 in human endothelial cells. Arterioscler Thromb. Vasc. Biol. 18:894-901.

2. Hishikawa, K., and Luscher, T.F. 1997. Pulsatile stretch stimulates superoxide production in human aortic endothelial cells. Circulation 96:3610-3616.

3. Wung, B.S., et al. 1996. Cyclic strain increases monocyte chemotactic protein-1 secretion in human endothelial cells. Am. J. Physiol. 270:H1462-H1468

4. Sumpio, B.E., and Widmann, M.D. 1990. Enhanced production of an endothelium-derived contracting factor by endothelial cells subjected to pulsatile stretch. Surgery. 108:277-282.

5. Naruse, K., and Sokabe, M. 1993. Involvement of stretch-activated ion channels in $\mathrm{Ca}^{2+}$ mobilization to mechanical stretch in endothelial cells. Am. J. Physiol. 264:C1037-C1044.

6. Rosales, O.R., Isales, C.M., Barrett, P.Q., Brophy, C., and Sumpio, B.E. 1997. Exposure of endothelial cells to cyclic strain induces elevations of cytosolic $\mathrm{Ca}^{2+}$ concentration through mobilization of intracellular and extracellular pools. Biochem. J. 326:385-392.

7. Naruse, K., Sai, X., Yokoyama, N., and Sokabe, M. 1998. Uni-axial cyclic stretch induces c-src activation and translocation in human endothelial cells via SA channel activation. FEBS Lett. 441:111-115.

8. Du, W., Mills, I., and Sumpio, B.E. 1995. Cyclic strain causes heterogeneous induction of transcription factors, AP-1, CRE binding protein and $\mathrm{NF}-\kappa \mathrm{B}$, in endothelial cells: species and vascular bed diversity. J. Biochem. 28:1485-1491.

9. Nakos, G., Pneumatikos, J., Tsangaris, I., Tellis, C., and Lekka, M. 1997. Proteins and phospholipids in BAL from patients with hydrostatic pulmonary edema. Am. J. Respir. Crit. Care Med. 155:945-951.

10. Parker, J.C., and Ivey, C.L. 1997. Isoproterenol attenuates high vascular pressure-induced permeability increases in isolated rat lungs. J. Appl. Physiol. 83:1962-1967.

11. Ying, X., Minamiya, Y., Fu, C., and Bhattacharya, J. 1996. $\mathrm{Ca}^{2+}$ waves in lung capillary endothelium. Circ. Res. 79:898-908.

12. McEver, R.P., Beckstead, J.H., Moore, K.L., Marshall-Carlson, L., and Bainton, D.F. 1989. GMP 140, a platelet alpha-granule membrane protein, is also synthesized by vascular endothelial cells and is localized in Weibel-Palade bodies. J. Clin. Invest. 84:92-99.

13. Datta, Y.H., et al. 1995. Peptido-leukotrienes are potent agonists of von Willebrand factor secretion and P-selectin surface expression in human umbilical vein endothelial cells. Circulation. 92:3304-3311.

14. Bless, N.M., et al. 1998. Differing patterns of P-selectin expression in lung injury. Am. J. Pathol. 153:1113-1122.

15. Nishio, K., et al. 1998. Differential contribution of various adhesion molecules to leukocyte kinetics in pulmonary microvessels of hyperoxiaexposed rat lungs. Am. J. Respir. Crit. Care Med. 157:599-609.

16. Hattori, R., Hamilton, K.K., Fugate, R.D., McEver, R.D., and Sims, P.J. 1989. Stimulated secretion of endothelial von Willebrand factor is accompanied by rapid redistribution to the cell surface of the intracellular granule membrane protein GMP-140. J. Biol. Chem. 264:7768-7771.

17. Ley, K., et al. 1995. Sequential contribution of L- and P-selectin to leukocyte rolling in vivo. J. Exp. Med. 181:669-675.

18. Chizmadzhev, Y.A., Cohen, F.S., Shcherbakov, A., and Zimmerberg, J. 1995. Membrane mechanics can account for fusion pore dilation in stages. Biophys. J. 69:2489-2500.

19. Peters, C., and Mayer, A. 1998. $\mathrm{Ca}^{2+} /$ calmodulin signals the completion of docking and triggers a late step of vacuole fusion. Nature. 396:575-580.

20. Betz, W.J., Mao, F., and Bewick, G.S. 1992. Activity dependent fluorescent staining and destaining of living vertebrate motor nerve terminals. J. Neurosci. 12:363-375

21. Betz, W.J., and Bewick, G.S. 1992. Optical analysis of synaptic vesicle recycling at the frog neuromuscular junction. Science. 255:200-203.

22. Hay, M., and Hasser, E.M. 1998. Measurement of synaptic vesicle exocytosis in aortic baroreceptor neurons. Am. J. Physiol. 275:H710-H716.

23. Kraszewski, K., Daniell, L., Mundigl, O., and De Camilli, P. 1996. Mobility of synaptic vesicles in nerve endings monitored by recovery from photobleaching of synaptic vesicle-associated fluorescence. J. Neurosci. 16:5905-5913.

24. Giovanucci, D.R., Yule, D.I., and Stuenkel, E.L. 1998. Optical measurement of stimulus-evoked membrane dynamics in single pancreatic acinar cells. Am. J. Physiol. 275:C732-C739.

25. Smith, C.B., and Betz, W.J. 1996. Simultaneous independent measurement of endocytosis and exocytosis. Nature. 380:531-534.

26. Walter, U.M., et al. 1997. Characterization of a novel adhesion function blocking monoclonal antibody to rat/mouse P-selectin generated in the P-selectin deficient mouse. Hybridoma. 16:249-257.

27. Dobbs, L.G., Williams, M.C., and Gonzalez, R. 1988. Monoclonal antibodies specific to apical surfaces of rat alveolar type I cells bind to surfaces of cultured, but not freshly isolated, type II cells. Biochim. Biophys. Acta. 970:146-156.

28. Morrell, N.W., Atochina, E.N., Morris, K.G., Danilov, S.M., and Stenmark, K.R. 1995. Angiotensin converting enzyme expression is increased in small pulmonary arteries of rats with hypoxia-induced pulmonary hypertension. J. Clin. Invest. 96:1823-1833.

29. Grynkiewicz, G., Poenie, M., and Tsien, R.Y. 1985. A new generation of $\mathrm{Ca}^{2+}$ indicators with greatly improved fluorescence properties. J. Biol. Chem. 260:3440-3450.

30. Hamill, O.P., and McBride, D.W., Jr. 1996. The pharmacology of mechanogated membrane ion channels. Pharmacol. Rev. 48:231-252.

31. Yang, G.-G., Sadurski, R., and Bhattacharya, J. 1993. Hemodynamic effects of brief pulmonary hemostasis. J. Appl. Physiol. 75:948-954.

32. Bhattacharya, J., and Staub, N.C. 1980. Direct measurement of microvascular pressure in the isolated perfused dog lung. Science. 210:327-328.

33. Stenberg, P.E., McEver, R.P., Shuman, M.A., Jacques, Y.V., and Bainton, D.F. 1985. A platelet alpha-granule membrane protein (GMP-140) is expressed on the plasma membrane after activation. J. Cell Biol. 101:880-886.

34. Tsukada, H., et al. 1995. Ligation of endothelial $\alpha_{v} \beta_{3}$ integrin increases capillary hydraulic conductivity of rat lung. Circ. Res. 77:651-659.

35. Subramaniam, M., Koedam, J.A., and Wagner, D.D. 1993. Divergent fates of P- and E-selectins after their expression on the plasma membrane. Mol. Biol. Cell. 4:791-801.

36. Green, S.A., Setiadi, H., McEver, R.P., and Kelly, R.B. 1994. The cytoplas- 
mic domain of P-selectin contains a sorting determinant that mediates rapid degradation in lysosomes. J. Cell Biol. 124:435-448.

37. Rosenkranz, A.R., Mendrick, D.L., Cotran, R.S., and Mayadas, T.N. 1999.

P-selectin deficiency exacerbates experimental glomerulonephritis: a protective role for endothelial P-selectin in inflammation. J. Clin. Invest. 103:649-659.

38. Mayadas, T.N., Johnson, R.C., Rayburn, H., Hynes, R.O., and Wagner, D.D. 1993. Leukocyte rolling and extravasation are severely compromised in P selectin-deficient mice. Cell. 74:541-554.

39. Weibel, E.R., and Palade, G.E. 1964. New cytoplasmic components in arterial endothelia. J. Cell Biol. 23:101-112.

40. Ghitescu, L., and Bendayan, M. 1992. Transendothelial transport of serum albumin: a quantitative immunocytochemical study. J. Cell Biol. 117:745-755.

41. Middleton, J., et al. 1997. Transcytosis and surface presentation of IL-8 by venular endothelial cells. Cell. 91:385-395.

42. Mulligan, M.S., et al. 1992. Neutrophil dependent lung injury. Requirement for P-selectin (GMP-140). J. Clin. Invest. 90:1600-1607.

43. Moore, T.M., Khimenko, P., Adkins, W.K., Miyasaka, M., and Taylor, A.E. 1995. Adhesion molecules contribute to ischemia and reperfusioninduced injury in the isolated rat lung. J. Appl. Physiol. 78:2245-2252.

44. Kameda, H., et al. 1997. Re-expression of functional P-selectin molecules on the endothelial cell surface by repeated stimulation with thrombin. Br. J. Haematol. 97:348-355.

45. Sakamaki, F., et al. 1995. Soluble form of P-selectin in plasma is elevated in acute lung injury. Am. J. Respir. Crit. Care Med. 151:1821-1826.

46. Verhaar, M.C., et al. 1998. Progressive vascular damage in hypertension is associated with increased levels of circulating P-selectin. J. Hypertens. 16:45-50

47. Kuebler, W.M., Kuhnle, G.E.H., Groh, J., and Goetz, A.E. 1994. Leukocyte kinetics in pulmonary microcirculation: intravital fluorescence microscopic study. J. Appl. Physiol. 76:65-71.

48. Kuebler, W.M., Kuhnle, G.E.H., Groh, J., and Goetz, A.E. 1997. Contribution of selectins to leukocyte sequestration in pulmonary microvessels by intravital microscopy in rabbits. J. Physiol. 501:375-386.

49. McDonald, D.A. 1952. The occurrence of turbulent flow in the rabbit aorta. J. Physiol. 118:340-347.

50. Lien, D.C., et al. 1987. Physiological neutrophil sequestration in the lung: visual evidence for localization in capillaries. J. Appl. Physiol. 62:1236-1243.

51. Armstead, V.E., Minchenko, A.G., Campbell, B., and Lefer, A.M. 1997. Pselectin is up-regulated in vital organs during murine traumatic shock. FASEB J. 11:1271-1279.

52. Qiao, R.L., and Bhattacharya, J. 1991. Segmental barrier properties of the pulmonary microvascular bed. J. Appl. Physiol. 64:2562-2567.

53. Raj, J.U., and Anderson, J. 1990. Pulmonary venous responses to thromboxane A2 analogue and atrial natriuretic peptide in lambs. Circ. Res. 66:496-502.

54. Bhattacharya, J. 1998. Physiological basis of pulmonary edema. In Lung biology in health and disease. Volume 116. M. Matthay and D. Ingbar, editors. Marcel Dekker. New York, NY. 1-36.

55. Ehrhart, I.C., and Hofman, W.F. 1992. Pressure-dependent increase in lung vascular permeability to water but not protein. J. Appl. Physiol. 72:211-218.

56. Minnear, F.L., Barie, P.S., and Malik, A.B. 1983. Effects of transient pulmonary hypertension on pulmonary vascular permeability. J. Appl. Physiol. 55:983-989.

57. West, J.B., Tsukimoto, K., Mathieu-Costello, O., and Prediletto, R. 1991. Stress failure in pulmonary capillaries. J. Appl. Physiol. 70:1731-1742.

58. Neal, C.R., and Michel, C.C. 1996. Openings in frog microvascular endothelium induced by high intravascular pressures. J. Physiol. 492:39-52.

59. Maron, M.B. 1989. Effect of elevated vascular pressure transients on protein permeability in the lung. J. Appl. Physiol. 67:305-310.

60. Cohen, A.B., et al. 1993. Neutrophil-activating peptide- 2 in patients with pulmonary edema from congestive heart failure or ARDS. Am. J. Physiol. 264:L490-L495.

61. Kubo, K., et al. 1998. Inflammatory cytokines in BAL fluid and pulmonary hemodynamics in high-altitude pulmonary edema. Respir. Physiol. 111:301-310.

62. Kubo, K., et al. 1996. Cytokines in bronchoalveolar lavage fluid in patients with high altitude pulmonary edema at moderate altitude in Japan. Thorax. 51:739-742.

63. He, P., Zhang, X., and Curry, F.E. 1996. $\mathrm{Ca}^{2+}$ entry through conductive pathway modulates receptor-mediated increase in microvessel permeability. Am. J. Physiol. 271:H2377-H2387. 